\title{
Simultaneous Release of Glutamate and Acetylcholine from Single Magnocellular "Cholinergic" Basal Forebrain Neurons
}

\author{
Timothy G. J. Allen, Fe C. Abogadie, and David A. Brown \\ Department of Pharmacology, University College London, London WC1E 6BT, United Kingdom
}

\begin{abstract}
Basal forebrain $(\mathrm{BF})$ neurons provide the principal cholinergic drive to the hippocampus and cortex. Their degeneration is associated with the cognitive defects of Alzheimer's disease. Immunohistochemical studies suggest that some of these neurons contain glutamate, so might also release it. To test this, we made microisland cultures of single BF neurons from 12- to 14-d-old rats. Over 1- 8 weeks in culture, neuronal processes made autaptic connections onto the neuron. In 34 of 36 cells tested, a somatically generated action potential was followed by a short-latency EPSC that was blocked by $1 \mathrm{~mm}$ kynurenic acid, showing that they released glutamate. To test whether the same neuron also released acetylcholine, we placed a voltage-clamped rat myoball expressing nicotinic receptors in contact with a neurite. In six of six neurons tested, the glutamatergic EPSC was accompanied by a nicotinic (hexamethonium-sensitive) myoball current. Stimulation of the $\mathrm{M}_{2}$-muscarinic presynaptic receptors (characterized using tripitramine and pirenzepine) produced a parallel inhibition of autaptic glutamatergic and myoball nicotinic responses; metabotropic glutamate receptor stimulation produced similar but less consistent and weaker effects. Atropine enhanced the glutamatergic EPSCs during repetitive stimulation by $25 \pm 6 \%$; the anti-cholinesterase neostigmine reduced the train EPSCs by $37 \pm 6 \%$. Hence, synaptically released acetylcholine exerted a negative-feedback inhibition of coreleased glutamate. We conclude that most cholinergic basal forebrain neurons are capable of releasing glutamate as a cotransmitter and that the release of both transmitters is subject to simultaneous feedback inhibition by synaptically released acetylcholine. This has implications for BF neuron function and for the use of cholinesterase inhibitors in Alzheimer's disease.
\end{abstract}

Key words: basal forebrain; cholinergic neuron; glutamate; acetylcholine (ACh); neurotransmitter; presynaptic regulation

\section{Introduction}

The cholinergic neurons of the basal forebrain (BF) provide a widespread excitatory projection to the cerebral cortex and hippocampus (Mesulam et al., 1983). They are involved in various higher cortical functions such as the maintenance of attention and wakefulness and the processing of short- and long-term memory (for review, see Wenk, 1997; Zaborszky et al., 1999; Lucas-Meunier et al., 2003). Moreover, their degeneration is one of the most highly correlated and consistent features associated with the loss of cognitive function in Alzheimer's disease (Perry et al., 1978; Whitehouse et al., 1982; Coyle et al., 1983).

However, some of the effects of BF degeneration may not solely result from a loss of acetylcholine. Thus, in addition to a substantial GABAergic component to this projection (Zaborszky et al., 1986; Gritti et al., 1993, 1997; Furuta et al., 2004), there is evidence for an important glutamatergic component (Gritti et al., 1993; Manns et al., 2001, 2003). Furthermore, a proportion, at least, of BF neurons appear to contain both ACh and glutamate, as judged from immunocytochemistry and single-cell reverse transcriptase-PCR analysis for specific markers (Manns et al.,

Received Sept. 20, 2005; revised Nov. 14, 2005; accepted Dec. 18, 2005.

This work was supported by Grant PG7909913 from the UK Medical Research Council and Grant 038170 from the Wellcome Trust.

Correspondence should be addressed to Prof. David A. Brown, Department of Pharmacology, University College London, Gower Street, London WC1E 6BT, UK. E-mail: d.a.brown@ucl.ac.uk.

D01:10.1523/JNEUROSCI.3979-05.2006

Copyright $\odot 2006$ Society for Neuroscience $\quad$ 0270-6474/06/261588-08\$15.00/0
2001; Gritti et al., 2003; Sotty et al., 2003). There is also some experimental evidence to suggest that both of these transmitters might be released from $\mathrm{BF}$ axons/terminals. Thus, repetitive stimulation of cholinergic afferents to pyramidal cells in hippocampal slices or slice cultures typically evokes a train of fast EPSPs/EPSCs (most probably glutamatergic) followed by an IPSP/IPSC and a slow cholinergic EPSP/EPSC lasting 20-30 s (Benardo and Prince, 1982; Haas, 1982; Cole and Nicoll, 1984; Gahwiler and Brown, 1985). Corelease of ACh and glutamate has also been reported from a choline acetyltransferase affinitypurified preparation of cortical cholinergic synaptosomes (Docherty et al., 1987).

Nevertheless, these experiments do not unequivocally demonstrate that both neurotransmitters are released simultaneously from the same neuron. This is difficult to test in situ, not least because the postsynaptic responses to the two transmitters differ greatly in time course and mechanism: glutamate produces a fast ionotropic response, whereas ACh produces a slow, G-proteinmediated effect via muscarinic receptors.

In previous experiments, we circumvented the problem of recording ACh release by using cultured BF neurons and then creating an "artificial nicotinic synapse" with a skeletal myoball, so that ACh release from BF neuron processes is detected as a fast nicotinic current (Allen and Brown, 1996; Allen, 1999). In the present experiments, we have combined this approach with the "microisland" method to culture single BF neurons (Landis, 1976; Potter et al., 1980; Bekkers and Stevens, 1991; Segal, 1991). 
The neuron then forms multiple autaptic contacts onto its own dendrites. As the neurons possess abundant ionotropic (AMPA and NMDA) glutamate receptors (Page and Everitt, 1995; Waters and Allen, 1998), any release of glutamate at the autapses will yield a conventional glutamatergic "synaptic" current. In this way, we show that individual cholinergic BF neurons can simultaneously release both $\mathrm{ACh}$ and glutamate and that the release of both transmitters is subject to powerful auto-inhibition by the released $\mathrm{ACh}$, mediated by presynaptic $\mathrm{M}_{2}$-muscarinic receptors.

\section{Materials and Methods}

Microisland cultures. Microisland cultures were prepared in $35 \mathrm{~mm}$ plastic Petri dishes. Their surface was first made nonpermissive for cell attachment by coating with a thin layer of agarose. Specifically, a $0.15 \%$ solution of agarose type II (Sigma, St. Louis, MO) in distilled water was prepared by heating in a microwave until the agarose was fully melted. A drop of this solution was then spread onto the surface of each Petri dish. As the solution cooled, the height of each drop was reduced as much as possible by removing excess solution with a pipette before the agarose gelled. The dishes were then allowed to thoroughly air dry overnight at room temperature. A mixture of $0.25 \mathrm{mg} \cdot \mathrm{ml}^{-1}$ poly-D-lysine $(75,000-$ 150,000 molecular weight; Sigma) and $0.5 \mathrm{mg} \cdot \mathrm{ml}^{-1}$ collagen (rat tail type I; Sigma) was then spotted onto the dishes using a glass atomizer (Thomas Scientific, Swedesboro, NJ) to create islands of permissive substrate ranging in diameter from 65 to $400 \mu \mathrm{m}$. Before use, the dishes were sterilized briefly under strong UV light for 3-5 min.

Preparation of basal forebrain neurons. A dissociated cell suspension of basal forebrain neurons was prepared as reported previously (Allen and Brown, 2004). Briefly, 12- to 14-d-old Sprague Dawley rat pups were anesthetized by chloroform inhalation before decapitation according to Home Office guidelines. The brain was removed rapidly and placed into ice-cold DMEM supplemented with $8 \mathrm{mM} \mathrm{Mg}^{2+}$ and $0.6 \%$ glucose. The brain was hemisected and $450-\mu \mathrm{m}$-thick coronal sections cut using a McIllwain tissue chopper. Basal forebrain areas, namely, the medial septum (MS), diagonal band of Broca (DBB), and substantia innominata (SI), were isolated and placed into HBSS containing $10 \mathrm{~mm}$ HEPES and $1.25 \mathrm{mg} \cdot \mathrm{ml}^{-1}$ trypsin and incubated for $60 \mathrm{~min}$ at $37^{\circ} \mathrm{C}$. The tissue fragments were subsequently washed in HBSS containing $10 \%$ fetal bovine serum (FBS) and $8 \mathrm{mM} \mathrm{Mg}^{2+}$ before being gently dissociated using a flamed Pasteur pipette. The resulting cell suspension was centrifuged at $600 \mathrm{rpm}$ for $6 \mathrm{~min}$, the supernatant discarded, and the cell pellet resuspended in Neurobasal medium containing B27 supplement (Invitrogen,

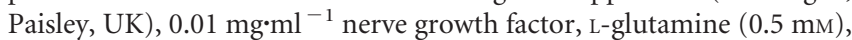
and $10 \%$ FBS. Cells were plated onto the dishes, prepared as detailed above, and left to settle for $2-3 \mathrm{~h}$ before the entire dish was gently flooded with medium. The medium was then replaced after $4 \mathrm{~h}$ to remove as much cellular debris as possible. Subsequent refeeding took place after $18 \mathrm{~h}$ and thereafter weekly with medium of the same composition minus FBS. Cells were maintained at $37^{\circ} \mathrm{C}$ in a $5 \% \mathrm{CO}_{2}$ incubator for periods of up to 8 weeks before use.

Preparation of skeletal myoball cultures. The method for preparing loosely adherent myoballs suitable for use as ACh detectors was as described previously (Allen, 1999).

Electrophysiology. Petri dishes bearing the microislands were transferred into a recording chamber mounted on stage of an Olympus (Melville, NY) BX50WI microscope equipped with Hoffman modulation optics and a fixed stage/moving microscope assembly. Unless otherwise stated, cells were superfused at a rate of $5-8 \mathrm{ml} \cdot \mathrm{min}^{-1}$ at room temperature $\left(22-26^{\circ} \mathrm{C}\right)$ with Krebs' solution of the following composition (in mM): $140 \mathrm{NaCl}, 3 \mathrm{KCl}, 2 \mathrm{CaCl}_{2}, 1.2 \mathrm{MgCl}_{2}, 12$ glucose, and 10 HEPES, adjusted to $\mathrm{pH} 7.3$ with $\mathrm{NaOH}$. Recordings were performed using either the tight-seal whole-cell or amphotericin-B perforated (Rae et al., 1991) patch-clamp technique and either an Axoclamp 2A or Axopatch 200A amplifier coupled to a Digidata 1200 (Molecular Devices, Union City, CA) interface and pClamp 8 (Molecular Devices) acquisition software. Data were acquired at a sampling rate of $10-40 \mathrm{kHz}$ and filtered at $1-5 \mathrm{kHz}$ (voltage clamp) or $20 \mathrm{kHz}$ (bridge voltage recording) before acquisition. When necessary, additional filtering was performed off-line. Patch pipettes were pulled from 1.5-mm-outer-diameter $\times$ 1.17-mm-inner-diameter borosilicate glass (Harvard Apparatus, Holliston, MA) coated to within $100 \mu \mathrm{m}$ of the tip with Sylgard (Dow Corning, Midland, MI). Electrode resistance ranged between 5 and $9 \mathrm{M} \Omega$ for whole-cell and 3 and $5 \mathrm{M} \Omega$ for perforated-patch recording. The composition of the pipette solution (unless otherwise stated) was the following (in mM): $108 \mathrm{~K}$ acetate, $11 \mathrm{KCl}, 40$ HEPES, $17 \mathrm{NaOH}, 3$ EGTA, 0.52 $\mathrm{CaCl}_{2}$, and $1.2 \mathrm{MgCl}_{2}, \mathrm{pH}$ 7.3. During perforated-patch recording from neuronal microislands using the Axoclamp 200A amplifier, series resistance values after compensation (50-75\%) ranged between 6 and $11 \mathrm{M} \Omega$.

Data acquisition and analysis. Data were analyzed using a combination of the pClamp 8 suite of software (Molecular Devices), Origin 5 (Microcal Software, Northampton, MA), and CorelDraw 10 (Corel, Ottawa, Ontario, Canada). Unless otherwise stated, all values are mean \pm SEM.

Drugs. All drugs were applied either via the superfusing solution or by inclusion in the pipette filling solution. Agarose IIA, acetylcholine chloride, $\mathrm{D}(-)$-2-amino-5-phosphonopentanoic acid (D-AP-5), atropine, diazoxide, glycine, hexamethonium, kynurenic acid, $N$-methyllycaconitine (MLA), methoctramine, ( \pm )-muscarine chloride, 1,2,3,4tetrahydro-6-nitro-2,3-dioxo-benzo[f] quinoxaline-7-sulfonamide disodium salt (NBQX), \pm - $\alpha$-methyl-(4-carboxyphenyl)glycine (MCPG), neostigmine, oxotremorine- $\mathrm{M}$, pirenzepine, trans- $(1 S, 3 R)-( \pm)-1$-amino1,3-cyclopentanedicarboxylic acid (t-ACPD), and tolbutamide were purchased from Sigma. Tripitramine (1, 1, 24-tris[ $[5,11$-dihydro-6-oxo- $6 \mathrm{H}$ pyrido [2,3-b][1,4]-benzodiazepin-11-yl)carbonyl]methyl]-8, 17-dimethyl$1,8,17,24$-tetraazatetracosane tetraoxalate) was supplied as a generous gift by Prof. C. Melchiorre (University of Bologna, Bologna, Italy).

\section{Results}

\section{Basal forebrain neurons form functional glutamatergic autaptic contacts}

After a period of 5-6 d in microisland culture, individual BF neurons began to form functional synapses onto themselves (autapses). Over 2-8 weeks, synaptic responses became larger and more robust as the number of autaptic contacts increased (Fig. 1). Thus, brief (2-3 ms) depolarizing pulses applied to the cell soma through a patch pipette (Fig. $1 A$ ) induced an action potential in the soma (Fig. $1 B$ ). This was followed by a depolarizing postsynaptic potential (EPSP) as the first action potential propagated along the processes to the autaptic synapses (Fig. $1 B, C$ ); if sufficiently large, this EPSP generated a second action potential (Fig. $1 B)$. Under voltage clamp, the postsynaptic response was manifest by a short-latency (inward) EPSC (Fig. 1D). In all but 4 of 36 cells tested, the EPSP/EPSC was reversibly blocked by $1 \mathrm{mM}$ kynurenic acid (Fig. $1 B$ ), showing that it was caused by the action of released glutamate. In two of the remaining cells, the current was inhibited by $100 \mu \mathrm{M}$ picrotoxin, indicating that it was mediated by GABA (or possibly glycine); in two additional cells of the 36 , the EPSC required both kynurenic acid and picrotoxin for full inhibition, so resulted from the corelease of both glutamate and GABA/glycine.

Although EPSCs were primarily mediated by AMPA receptors, their decay phase was biphasic, with time constants of $4.57 \pm 0.3$ and $58.1 \pm 0.09 \mathrm{~ms}(n=35)$, the latter contributing $34 \pm 9 \%$ to the total synaptic current. The slowly declining phase was because of activation of NMDA receptors (Fig. 1C). Thus, after addition of 1-3 $\mu \mathrm{M}$ glycine in the absence of extracellular $\mathrm{Mg}^{2+}$ (to enhance NMDA-mediated currents), the fast component could be selectively inhibited by the AMPA antagonist NBQX, whereas the slow component was inhibited by the selective NMDA antagonist D-AP-5 (both at $100 \mu \mathrm{M}$; four cells) (Fig. $1 C, D)$. 
Individual neurons release both glutamate and acetylcholine

Are these glutamate-releasing neurons truly cholinergic? To test this, we placed a voltage-clamped myoball expressing nicotinic ACh receptors (nAChRs) in contact with the neurites of a cultured BF neuron while at the same time recording the autaptic EPSC from the soma (Fig. $2 A$ ). As shown in Figure 2, $B$ and $C$, on stimulating the neuron, we could then simultaneously record both a glutamatergic EPSC from the soma and a nicotinic current in the myoball. Kynurenic acid almost totally suppressed the somatically recorded EPSC without affecting the myoball current, whereas the nicotinic antagonist hexamethonium $(100 \mu \mathrm{M})$ selectively suppressed the myoball current. Thus, the same neuron released both glutamate (to generate a glutamatergic autaptic EPSC) and $\mathrm{ACh}$ (to activate the nicotinic receptors in the myoball). Such corelease was observed in all of the six neurons we were able to test in this manner.

In some cells (Fig. 2Ci), hexamethonium produced a small (mean, $7.3 \pm$ $3.3 \% ; n=5)$ reduction in the amplitude of the autaptic EPSC. Although this might be interpreted to suggest a minor cholinergic component to the compound EPSC, this seems unlikely for two reasons. First, only very small nicotinic currents (mean, $54.8 \pm$ $17.4 \mathrm{pA} ; n=19)$ could be evoked by somatic application of high concentrations of ACh (1 mM) onto these cells. These were most probably mediated by $\alpha 7$ subunit-containing receptors, because they were replicated by focally applied choline (1-10 mM), desensitized by bath application of choline (30-100 $\mu \mathrm{M})$, and blocked by MLA (3-10 nM). In only one of a total of 20 cells tested did ACh evoked a much larger (967 pA) MLA-resistant current. Second, hexamethonium did not produce any further reduction of the residual postsynaptic current seen after suppressing the glutamatergic component of the EPSC with kynurenic acid. Hence, the effect of hexamethonium illustrated in Figure 2Ci is most likely the result of a weak inhibitory effect on glutamate receptors.

\section{Presynaptic $\mathrm{M}_{2}$ muscarinic receptors inhibit both ACh and glutamate release}

We have shown previously that release of ACh from the processes of $\mathrm{BF}$ neurons in culture is strongly suppressed by stimulating the $\mathrm{M}_{2}$ muscarinic ACh receptors (mAChRs) present on these neurons (Allen and Brown, 1996) and that this probably results from inhibition of the presynaptic N- and P/Q-type $\mathrm{Ca}^{2+}$ channels (Allen, 1999). We therefore asked whether activating these receptors could also inhibit glutamate release at autapses. Figure $2 D$ indicates that this was indeed the case: application of the muscarinic agonist muscarine $(10 \mu \mathrm{M})$ produced a parallel suppression of both the glutamatergic EPSC and the simultaneously recorded myoball nicotinic current (mean inhibition, $93.1 \pm 2.3$ and $96.9 \pm 1.2 \%$, respectively; $n=6$ ). Muscarinic inhibition of the glutamatergic EPSC was concentration dependent (Fig. $3 A$ ). The $\mathrm{IC}_{50}$ values for muscarine, oxotremorine- $\mathrm{M}$, and $\mathrm{ACh}$ (in the presence of $3 \mathrm{~nm} N$-methyllcaconitine) were $0.49 \pm 0.10,0.38 \pm$ 0.11 , and $0.40 \pm 0.15 \mu \mathrm{M}$, respectively ( $n=5-7$ in each case).

A
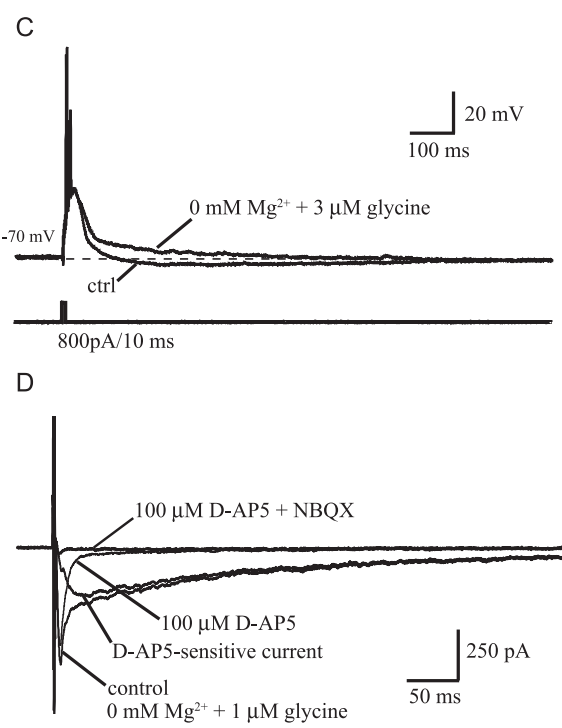

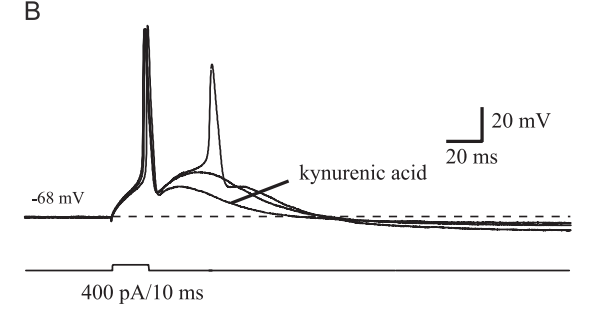

Figure 1. A, A typical microisland visualized using Normarski differential interference contrast optics. The neuron shown was generated by a brief ( $10 \mathrm{~ms}, 400 \mathrm{pA}$ ) current injection are followed by autaptic EPSPs, one of which generates a second action potential. The autaptic EPSP is attenuated by $1 \mathrm{~mm}$ kynurenic acid. [The residual, kynurenic acid-insensitive ADP results from responses were enhanced by removal of extracellular $\mathrm{Mg}^{2+}$ and the addition of $3 \mu \mathrm{m}$ glycine. (Note the slower time base.) $\mathrm{ctrl}$, control. D, Voltage-clamp recording of autaptic EPSCs in $0\left[\mathrm{Mg}^{2+}\right], 1 \mu \mathrm{m}$ glycine solution. The EPSC comprises fast and slow components. The NMDA antagonist D-AP-5 (100 $\mu \mathrm{m})$ selectively inhibited the slow component; the subtracted D-AP-5-sensitive current shows the characteristic slow rise time and decay of an NMDA current. The residual fast component was inhibited by the AMPA receptor antagonist NBQX (100 $\mu \mathrm{M})$.

These $\mathrm{IC}_{50}$ values for $\mathrm{ACh}$ and oxotremorine-M are similar to those determined previously for the inhibition of the somatic $\mathrm{Ca}^{2+}$ current in BF neurons (0.2 and $0.36 \mu \mathrm{M}$, respectively) (Allen and Brown, 1993).

We also determined the subtype of muscarinic receptor responsible for inhibition of glutamate release, using ACh as agonist and the antagonists pirenzepine and tripitramine (which are relatively selective for $M_{1} / M_{4}$ and $M_{2}$ receptors, respectively) (Caulfield and Birdsall, 1998). Mean $\mathrm{IC}_{50}$ values for AChinduced EPSC inhibition in the presence of $100 \mathrm{~nm}$ pirenzepine or $3 \mathrm{nM}$ tripitramine were $0.64 \pm 0.017 \mu \mathrm{M}(n=7)$ and $8.47 \pm 2.4$ $\mu \mathrm{M}(n=6)$, respectively (Fig. $3 B)$. Antagonist dissociation equilibrium constants $\left(K_{\mathrm{B}}\right.$, nanomolar) were calculated from the standard competitive antagonism equation as follows: $r=1+$ $\left([\mathrm{B}] / K_{\mathrm{B}}\right)$, where $r$ is the ratio of the $\mathrm{ACh} \mathrm{IC}_{50}$ in the presence of antagonist to that in its absence, and $[\mathrm{B}]$ is the concentration of antagonist (nanomolar). Deduced values for $K_{\mathrm{B}}$ were as follows: pirenzepine, $166 \mathrm{~nm}$; tripitramine, $0.148 \mathrm{~nm}$. The ratio of these values (1121:1) is in good agreement with those reported previously for their relative affinities for $\mathrm{M}_{2}$ receptors (800:1 to 1250:1) (Caulfield and Birdsall, 1998). Hence, muscarinic inhibition of glutamate release is mediated by the same $\left(\mathrm{M}_{2}\right)$ subclass of receptor as that responsible for inhibiting the $\mathrm{Ca}^{2+}$ current (Allen and Brown, 1993) and ACh release from BF neurons (Allen and Brown, 1996).

\section{Synaptically released ACh inhibits glutamate release from the same BF neuron}

Because the evoked release of glutamate from BF neurons is inhibited by exogenously applied ACh (see above), we asked whether glutamate release might also be inhibited when ACh is coreleased from the same neuron. Our first test for this was simply to record the glutamatergic EPSC during low-frequency (2 
A

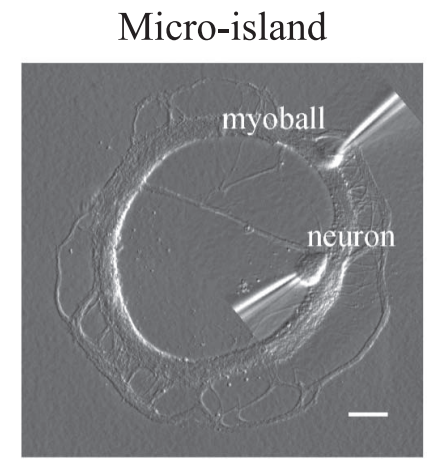

Glutamatergic EPSC

Myoball $\mathrm{I}_{\mathrm{nAChR}}$
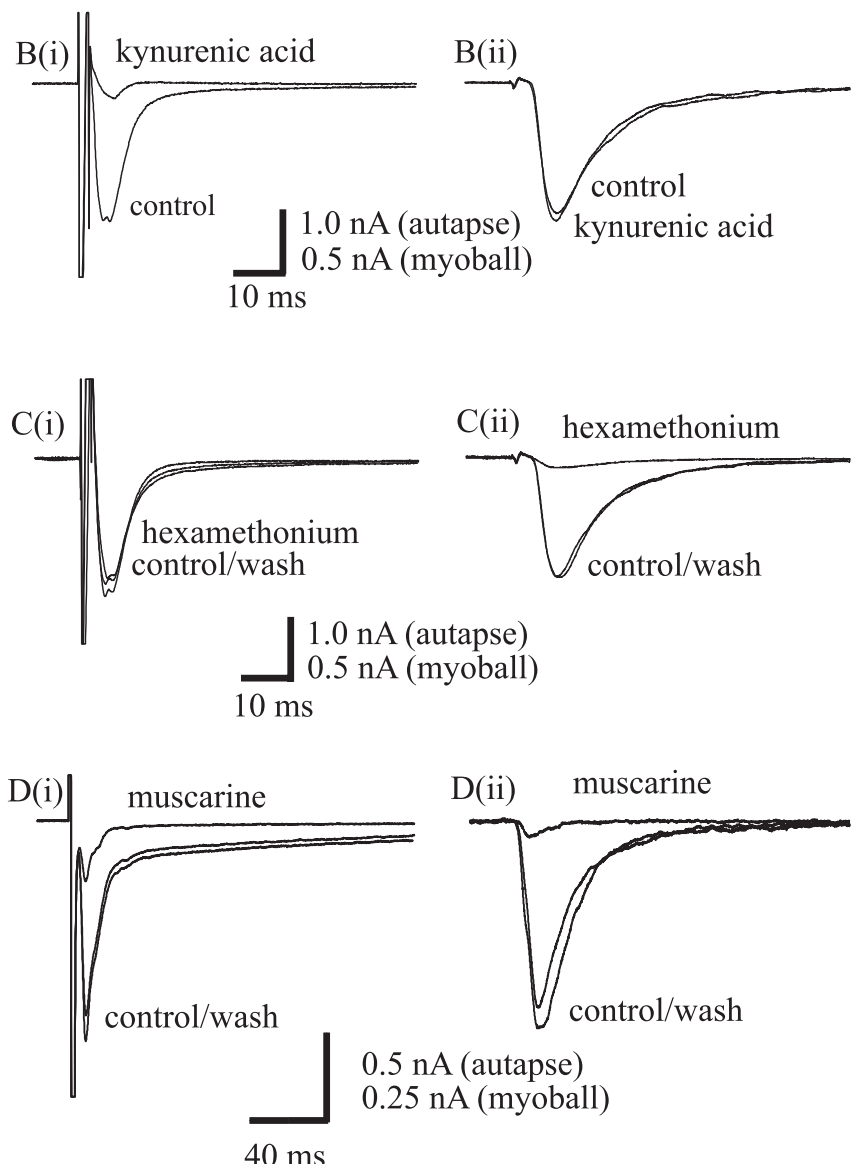

Figure 2. Corelease of glutamate and acetylcholine from single magnocellular basal forebrain neurons grown in microisland culture and suppression of their release by stimulating mAChRs. A, Photographic montage of a single-cell microisland from which the simultaneous release of glutamate (detected in the form of an autaptic EPSC by the neuronal recording electrode) and ACh (detected in the form of a nicotinic current in a voltage-clamped skeletal myoball placed in contact with the neurites of the cell) were detected from the same cell. Scale bar, $30 \mu \mathrm{m} . \mathbf{B i}$, Ci, Di, Glutamatergic autaptic EPSCs evoked by single action potentials elicited in response to a brief ( $2 \mathrm{~ms}$ ) depolarizing step from a holding potential of $-70 \mathrm{mV}$. Bii, Cii, Dii, Simultaneous release of ACh from the same cells detected using single perforated-patched skeletal myoballs voltage clamped at $-70 \mathrm{mV}$ and placed in contact with the neurites of the cell (Allen, 1999). Note that the records shown in $\boldsymbol{B}$ and $\boldsymbol{C}$ were obtained from the same neuron/ myoball pair; records in $\boldsymbol{D}$ are from a different neuron/myoball pair. $\ln \boldsymbol{B}$, the glutamate antagonist kynurenic acid (1 $\mathrm{mm}$ ) abolished the autaptic EPSC without affecting the myoball response. Conversely, in C, the nicotinic ACh-receptor antagonist hexamethonium (100 $\mu \mathrm{M})$ abolished the response of the myoball but had almost no effect on the autaptic EPSC. In D, the mAChR agonist muscarine $(10 \mu \mathrm{m})$ reversibly inhibits both glutamate and ACh release from a single neuron.
A

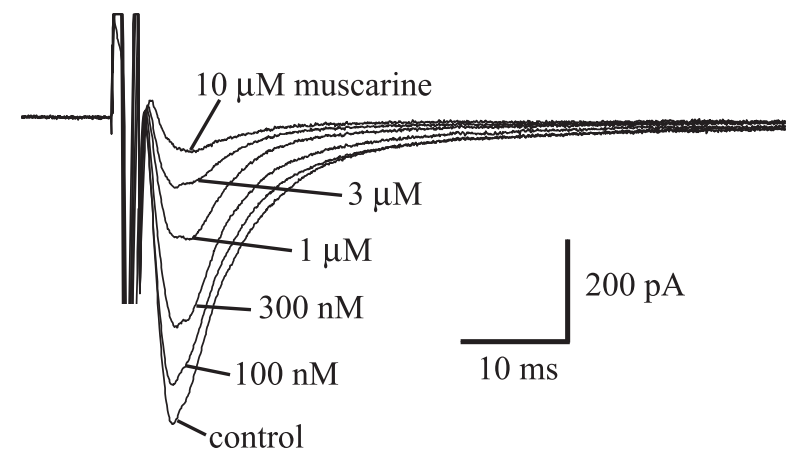

B

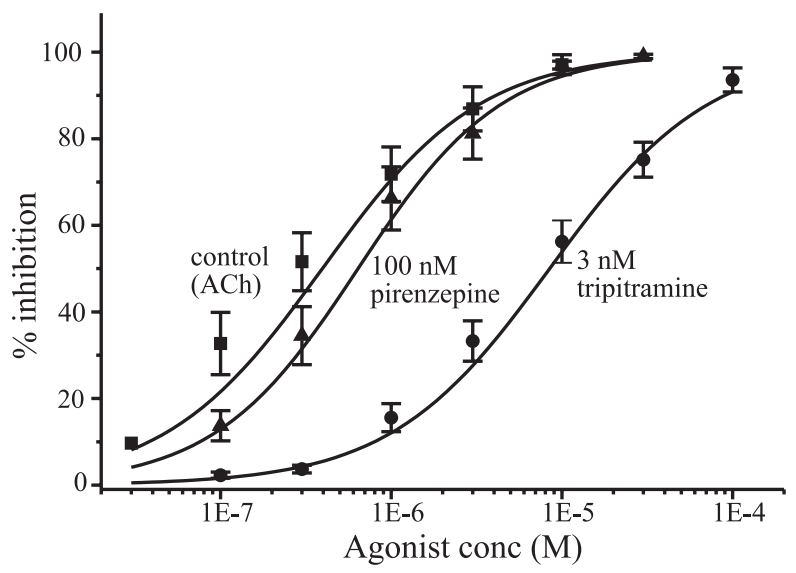

Figure 3. Muscarinic receptor-mediated inhibition of the glutamatergic autaptic EPSC. $\boldsymbol{A}$, EPSCs in a single cultured neuron in response to single action potentials elicited by imposing brief ( $2 \mathrm{~ms}$ ) depolarization steps from $V_{\mathrm{h}}-80 \mathrm{mV}$ under control conditions and in the presence of increasing concentrations of muscarine $(0.1-10 \mu \mathrm{M})$. Each response is an average of four to six EPSCs after equilibration at each of the different agonist concentrations. $\boldsymbol{B}$, Dose-response relationships for inhibition of EPSC by $A C h$ recorded under control conditions and the presence of the $M_{1} / M_{4} m A C h R$ antagonist pirenzepine or the $M_{2}$ antagonist tripitramine. Inhibition was measured as percentage reduction of peak EPSC amplitude. Curves are least-squares fits to the following Hill equation: $y=y_{\max } \times x^{n \mathrm{H}} /\left(x^{n \mathrm{H}}+K^{n \mathrm{H}}\right)$, where $y=$ percentage inhibition, $y_{\max }=100, x=$ agonist concentration (conc; micromolar), $K$ is a constant (equivalent to the $\mathrm{IC}_{50}$; micromolar), and $n_{\mathrm{H}}$ is the Hill slope. Fitted curves were constructed using the mean $\mathrm{IC}_{50}$ and Hill slope values obtained from the individual cells. All data points are the mean \pm SEM values obtained after normalization of data obtained from the individual cells ( $n=5-7$ cells for each point). Mean values for $K$ (micromolar; $n_{H}$ in parentheses) were as follows: control, $0.395 \pm 0.152$ (slope, 0.95 ); pirenzepine, $0.639 \pm 0.017$ (slope, 1.23); and tripitramine, $8.47 \pm 2.4$ (slope, 0.93 ).

$\mathrm{Hz}$ ) trains of stimuli delivered before and after adding the muscarinic antagonist atropine $(30-100 \mathrm{~nm})$. The EPSC declined substantially after the first stimulus but was then maintained at a steady, lower level throughout the rest of the train (Fig. 4A-C). Atropine did not affect the amplitude of the first EPSC (showing that it did not affect the postsynaptic action of glutamate) but consistently increased the amplitude of subsequent EPSCs, by on average $25 \pm 5.5 \%(n=4)$ (Fig. $4 C)$.

In the experiment illustrated in Figure $4, A$ and $B$, atropine produced full enhancement of the second EPSC, which was then sustained throughout the train of impulses. Thus, muscarinic receptor activation must have attained its full effect within the 
$500 \mathrm{~ms}$ between the first and second stimuli and then reached a steady state thereafter. To examine how rapidly the activation occurs, we repeated these experiments using $10 \mathrm{~Hz}$ stimuli delivered in short trains (to minimize transmitter depletion; see legend to Fig. 4). In this case, atropine had no effect on the first and second EPSCs but showed progressively increasing effects on the third and fourth EPSCs (mean enhancement of third and fourth EPSC amplitudes being $4.9 \pm 1.2$ and $10.9 \pm 2.8 \%$, respectively; $n=10$ ) (Fig. $4 D, E$ ). The fifth EPSC evoked $1 \mathrm{~s}$ later without intervening stimuli was still enhanced (mean increase, $23.7 \pm 5.9 \%$; $n=10$ ), showing that inhibition was sustained (Fig. $4 F$ ). Thus, this form of presynaptic inhibition had a delay of at least $100 \mathrm{~ms}$, a rise time of $\geq 200 \mathrm{~ms}$, and a duration of $>1 \mathrm{~s}$. It seems most likely that inhibition results from activation of $\mathrm{M}_{2}$ muscarinic receptor coupled to presynaptic $\mathrm{Ca}^{2+}$ channels by $\beta \gamma$ subunits of the $\mathrm{G}$-protein $\mathrm{G}_{\mathrm{o}}$ (Allen and Brown, 1996). The equivalent form of $\mathrm{mAChR}$-induced $\mathrm{Ca}^{2+}$ current inhibition in sympathetic neurons has an onset time constant of $\sim 1 \mathrm{~s}$ and a recover time constant of 6-10 s after rapid agonist application (Zhou et al., 1997). However, auto-inhibition in the CNS by a synaptically released transmitter can be somewhat faster than this (e.g., $\sim 0.2$ and $2 \mathrm{~s}$ for onset and offset of $\mathrm{GABA}_{\mathrm{B}}$-mediated inhibition in the hippocampus) (Pfrieger et al., 1994). Our observations match the latter quite well; at the very least, they imply that the site of ACh release must have been very close to the $\mathrm{Ca}^{2+}$ channels that triggered the release of glutamate.

The extent to which glutamate release would be inhibited by synaptically released ACh will not just depend on the local concentration but also the number of receptors it has access to. This in turn will depend on its lifetime before it is broken down by endogenous cholinesterases. To determine what influence cholinesterases exert on the strength of presynaptic inhibition, we examined the effect of the anti-cholinesterase drug neostigmine $(3 \mu \mathrm{M})$ on the amplitude of the glutamatergic EPSC, using the same short-train protocol illustrated in Figure 4D. Again, like atropine, it had no effect on the amplitude of the first two EPSCs but reduced the amplitude of all subsequent EPSCs. The mean inhibition of third, fourth, and fifth EPSC amplitudes were $10.8 \pm 1.3,15.8 \pm 1.9$, and $36.7 \pm$ $5.7 \%$, respectively $(n=12)$ (Fig. 5$)$. These effects were fully reversed by 30-100 nM atropine. Thus, inhibiting cholinesterase clearly intensified the cross-inhibitory effect of ACh on glutamate release.

\section{Do BF neurons possess presynaptic glutamate receptors?}

Because these neurons are both cholinergic and glutamatergic, the question arises whether, like some other glutamatergic neurons, they possess inhibitory presynaptic "metabotropic" glutamate receptors (mGluRs), in addition to presynaptic muscarinic receptors; and, if so, is there reciprocal mGluR-mediated inhibition of ACh release? We tested this using the mGluR agonist t-ACPD. t-ACPD $(30 \mu \mathrm{M})$ inhibited the glutamatergic EPSC in 12 of 21 cells tested (mean inhibition, $23.7 \pm 5.1 \% ; n=12$ ) and the myoball $\mathrm{nAChR}$ current in four of seven cells (mean inhibition, $50.1 \pm 13.8 \% ; n=4$ ). Of six neurons in which ACh and glutamate release from the same cell were recorded simultaneously, $\mathrm{t}$-ACPD inhibited the release of both transmitters in three cells (Fig. 6), ACh release alone in one cell, and had no effect in the remaining two cells. Thus, the effects of mGluRs differ from those of muscarinic AChRs in two important ways. First, they only inhibit release in a subpopulation of the cells. Second, the effects of $\mathrm{t}$-ACPD were much weaker than those of muscarinic agonists, which produced virtually complete inhibition of release of both transmitters in all of the neurons tested (see above). We also tested the effect of the mGluR antagonist MCPG $(30-300 \mu \mathrm{M})$ on evoked glutamatergic EPSCs but could detect no significant increase in EPSC amplitude in any of five cells tested.

We wondered why t-ACPD had such a weak effect. We therefore tested whether $\mathrm{t}-\mathrm{ACPD}$ affected the somatic $\mathrm{Ca}^{2+}$ current in the same manner as mAChR agonists (Allen and Brown, 1993). 
A

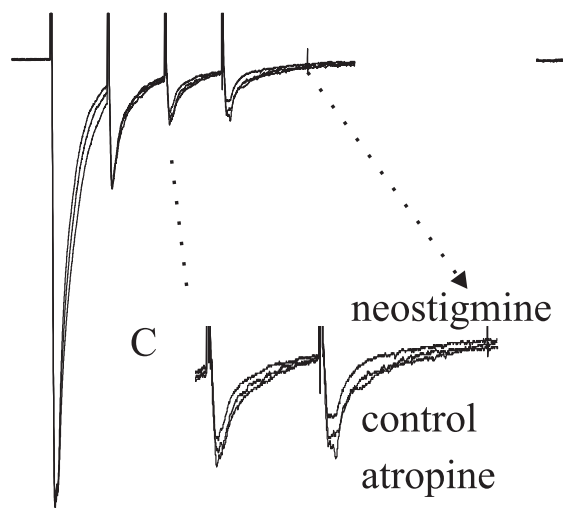

B

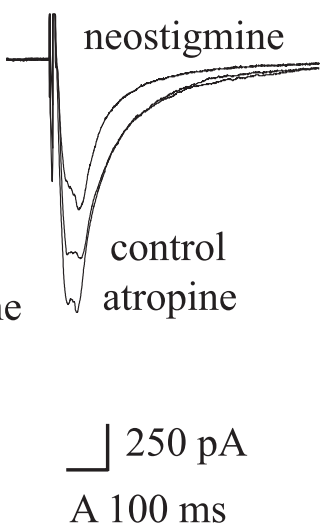

B $20 \mathrm{~ms}$

Figure 5. Effects of the anti-cholinesterase neostigmine $(3 \mu \mathrm{M})$ on presynaptic muscarinic receptor-mediated inhibition of glutamatergic EPSCS. $A$, Four EPSCs were evoked at a frequency of $10 \mathrm{~Hz}$, with a delay of $1 \mathrm{~s}$ before a fifth EPSC was elicited $(\boldsymbol{B})$. This protocol repeated every $60 \mathrm{~s}$. Addition of neostigmine had no effect on the initial two EPSCs but depressed all subsequent ones, including that recorded $1 \mathrm{~s}$ later $(\boldsymbol{B}, \boldsymbol{C})$. Addition of atropine (100 nM) in the presence of neostigmine fully reversed this effect and even enhanced the later EPSCS.

A

\section{Glutamatergic EPSC}

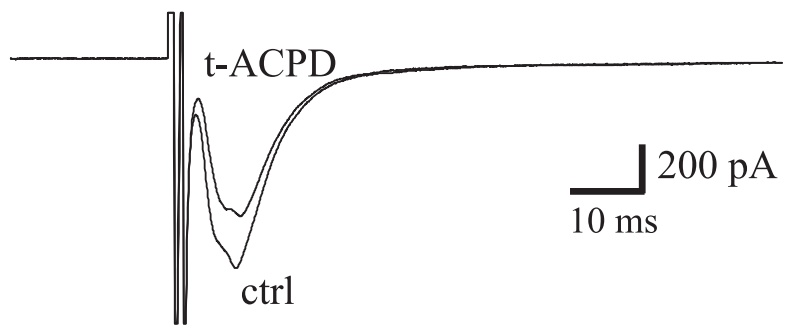

B

$$
\text { Myoball } \mathrm{I}_{\mathrm{nAChR}}
$$

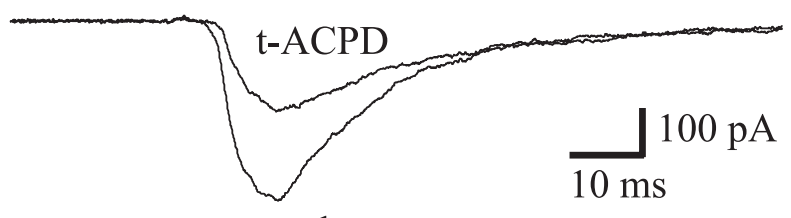

ctrl

Figure 6. Stimulation of presynaptic metabotropic glutamate receptors (mGluRs reduces the release of both glutamate and ACh). Records show the depressant effect of the mGluR agonist t-ACPD $(30 \mu \mathrm{M})$ on glutamatergic autaptic EPSCS $(\boldsymbol{A})$ and myoball nicotinic ACh currents $(\boldsymbol{B})$, respectively, recorded simultaneously on stimulating a single $\mathrm{BF}$ neuron in a microisland culture (see Fig. 2). Note that all records are the mean of four repetitions in the presence and absence of agonist. For clarity, washout responses have been omitted, but autaptic and myoball responses recovered to 97 and 103\%, respectively, of the control (ctrl) values.

Using perforated-patch recording and constructing currentvoltage curves by the protocol described previously, we found that $\mathrm{t}-\mathrm{ACPD}$, in concentrations up to $300 \mu \mathrm{M}$, had no effect on the $\mathrm{Ca}^{2+}$ current in 10 of 12 neurons tested, although $\mathrm{mAChR}$ agonists were fully effective under the same conditions and produced $<10 \%$ inhibition in the remaining two cells. We also

looked for other potential release-inhibiting effects that might be detectable by somatic recording, such as activation of inwardly rectifying $\mathrm{K}^{+}$currents, by constructing full current-voltage curves in the presence of tetrodotoxin using square voltage steps between -140 and $0 \mathrm{mV}$. We could not discern any effect of t-ACPD on the amplitudes or kinetics of the inward-rectifier, A-type, or delayed-rectifier $\mathrm{K}^{+}$currents on $\mathrm{K}_{\text {ATP }}$ currents (recorded in the presence and absence of the activator diazoxide) or on the "leak" $\mathrm{K}^{+}$current. We conclude either that the sample of neurons we used for these experiments did not possess somatic mGluRs or that the (irregular) effect of mGluR stimulation on evoked transmitter release stems from some other, perhaps intracellular, effect that differs from the effect of $\mathrm{mAChR}$ stimulation.

\section{Discussion}

The principle of cotransmission, the process whereby a neuron can store and release two or more different neurotransmitters, is now widely accepted (Burnstock, 2004). Corelease of ACh and glutamate has been described previously in Torpedo electric organ synaptosomes (Israel et al., 1993) and from amphibian neurons ( $\mathrm{Li}$ et al., 2004), and very recently, a component of the synaptic current at the classical nicotinic motoneuron-Renshaw cell synapse in the spinal cord has been attributed to the release of glutamate (Mentis et al., 2005; Nishimura et al., 2005).

In the latter experiments, detection of cotransmission at a single synapse was facilitated by the fact that both transmitters activated fast ionotropic receptors. Comparable experiments on $\mathrm{BF}$-cortical or hippocampal target cell synapses are not possible because, at these synapses, ACh stimulates slowly operating muscarinic ACh receptors. In the present experiments, we therefore converted the normal target synapse to a glutamatergic autapse and converted the muscarinic response to a nicotinic response with a myoball. In this way, we have unequivocally demonstrated the corelease of glutamate and $\mathrm{ACh}$ from single basal forebrain neurons. Virtually all of the BF neurons displayed short-latency fast autaptic EPSCs mediated by glutamate on stimulating the soma of the same neuron, and, in all six neurons so tested, an ACh-mediated nicotinic current could be simultaneously recorded in a detector myoball apposed to one of its processes. Moreover, even in the absence of direct recording of ACh release with the myoball, in an additional 14 cells, addition of atropine and/or neostigmine modified glutamatergic EPSCs in the manner expected for simultaneous corelease of ACh (see below).

Although autaptic connections are favored in microisland cultures (Mennerick et al., 1995), the high frequency of glutamate-mediated EPSCs seen on stimulating presumed cholinergic BF neurons is unlikely to be an artifact of culture, because glutamatergic EPSPs and EPSCs have also been noted to precede the slow cholinergic postsynaptic response of pyramidal cells in slices of adult hippocampus on stimulating afferents from the medial septum of the BF (Cole and Nicoll, 1984) or in long-term organotypic cultures (Gahwiler and Brown, 1985). What was not clear in those experiments was whether the glutamate and the ACh were released from axons of the same or different neurons. Our observations indicate that, in most cases at least, the two transmitters were likely to have been released from the same neuron. We have not been able to directly determine whether ACh and glutamate are coreleased from the same vesicles or release sites, because the BF neurons possess too few nicotinic receptors to permit simultaneous detection of a nicotinic component to the autaptic EPSC. However, the rapid time course of the cholinergic feedback inhibition of glutamate release would suggest a very close apposition of the release foci for the two transmitters. 
This raises the interesting question whether these neurons should be regarded as phenotypically cholinergic or glutamatergic neurons. This we cannot directly answer: we would only note that they correspond in all respects to those categorized previously as magnocellular cholinergic neurons. Thus, in previous experiments using these neurons in long-term culture, they showed the same electrophysiological properties as those reported for identified cholinergic BF neurons in situ (Allen and Brown, 1993; Sim and Allen, 1998) and released ACh from their processes (Allen and Brown, 1996). Furthermore, neurons isolated in the same manner, grown on the same substrate, and maintained in identical growth media as those used in the present experiments (albeit as mass cell cultures) expressed the cholinergic marker choline acetyltransferase as determined by singlecell PCR (Allen and Brown, 2004). In this respect, therefore, they belong to that class of $\mathrm{BF}$ neurons conventionally regarded as cholinergic.

Functionally, the corelease of glutamate with ACh from these neurons is likely to have several important consequences. First, it suggests that some re-evaluation of the role of BF neurons in regulating cortical and hippocampal excitability may be necessary. Thus, BF neurons have previously been considered to have a rather slow, tonic, and "diffusive" effect on cortical and hippocampal neuron activity (for review, see Harkany et al., 1999). This would accord with the slow and sustained effect of released ACh on the target pyramidal neurons (Cole and Nicoll, 1984; Gahwiler and Brown, 1985). However, the ability to generate fast EPSCs through corelease of glutamate would allow for additional, rapid, and more punctate effects, more closely geared to the discharge patterns of the BF neurons. Furthermore, because much of the cholinergic innervation is onto dendritic shafts as opposed to pyramidal cell bodies (Beaulieu and Somogyi, 1991; Umbriaco et al., 1994; Mrzljak et al., 1995), it is likely that ACh also modulates the active conductance properties of these dendrites to facilitate or attenuate throughput and summation of synaptic inputs from other sources. If some of these afferents also release glutamate, then this could provide an additional excitatory input with much faster onset and offset rates than that mediated by mAChRs.

Second, the release of glutamate raises the possibility of crossexcitation between cholinergic BF neurons. No such excitation would be likely to occur as a result of ACh release, because magnocellular BF neurons express predominantly $\mathrm{M}_{2} \mathrm{mAChRs}$, which are (if anything) inhibitory, and, as noted above, the density of nAChRs is too low to generate of fast EPSPs. However, within the MS-DBB region, many of the projecting cholinergic $\mathrm{BF}$ neurons give off axon collaterals that innervate other septohippocampal cholinergic and GABAergic neurons (Leranth and Frotscher, 1989). Thus, 93\% of the ChAT-positive neurons within the MS-DBB receive contacts from at least one vesicular glutamate transporter 2-containing bouton (Hajszan et al., 2004). This glutamatergic innervation has both extrinsic and intrinsic origins (Csaki et al., 2000, 2002; Fremeau et al., 2001; Manns et al., 2001; Kiss et al., 2002; Lin et al., 2003; Hajszan et al., 2004). Because the projections of individual septohippocampal neurons are topographically organized with relatively small terminal fields $(<1-1.5 \mathrm{~mm}$ in diameter) (Price and Stern, 1983), lateral interconnectivity within the MS-DBB mediated by glutamate could provide a mechanism for rapid radiation of excitation within the hippocampus. Furthermore, glutamatergic crosstransmission within the BF may be subject to negative-feedback regulation by coreleased $\mathrm{ACh}$ (see below), because glutamergic EPSCs recorded from BF neurons are subject to the same $\left(\mathrm{M}_{2}\right.$ - mediated) muscarinic inhibition as that observed at our autapses (Sim and Griffith, 1996). In addition, our finding that in a proportion of cells, activation of mGluRs attenuated the glutamatergic EPSC suggests that glutamate might be released and act presynaptically to modulate its own release (and possibly the release of ACh as well). However, we could not substantiate this because the mGluR blocking agent MCPG did not enhance glutamatergic EPSCs; this probably reflects the much weaker and less consistent effects of exogenously applied mGluR agonists compared with those produced by mAChR agonists.

Finally, it has long been established that the release of ACh from cholinergic projection neurons in the cortex is subject to very strong negative-feedback inhibition through the presynaptic $\mathrm{M}_{2}$ mAChRs (Dudar and Szerb, 1969). The present experiments show that this is accompanied by an equally strong feedback inhibition of glutamate release, mediated through the same $\left(\mathrm{M}_{2}\right)$ $\mathrm{mAChRs}$ as those responsible for the inhibition of ACh release and furthermore, that this is intensified by anti-cholinesterase drugs. This means that glutamate release may also be inhibited when attempts are made to use such drugs in the treatment of Alzheimer's disease. The consequent reduction of glutamatergic excitation may be one reason why these drugs appear to have rather limited effects.

\section{References}

Allen TGJ (1999) The role of N-, Q- and R-type $\mathrm{Ca}^{2+}$ channels in feedback inhibition of ACh release from rat basal forebrain neurons. J Physiol (Lond) 515:93-107.

Allen TGJ, Brown DA (1993) $\mathrm{M}_{2}$ muscarinic receptor-mediated inhibition of the $\mathrm{Ca}^{2+}$ current in rat magnocellular cholinergic basal forebrain neurones. J Physiol (Lond) 466:173-189.

Allen TGJ, Brown DA (1996) Detection and modulation of acetylcholine release from neurites of rat basal forebrain cells in culture. J Physiol (Lond) 492:453-466.

Allen TGJ, Brown DA (2004) Modulation of the excitability of cholinergic basal forebrain neurones by $\mathrm{K}_{\mathrm{ATP}}$ channels. J Physiol (Lond) 554:353-370.

Beaulieu C, Somogyi P (1991) Enrichment of cholinergic synaptic terminals on GABAergic neurons and coexistence of immunoreactive GABA and choline acetyltransferase in the same synaptic terminals in the striate cortex of the cat. J Comp Neurol 304:666-680.

Bekkers JM, Stevens CF (1991) Excitatory and inhibitory autaptic currents in isolated hippocampal neurons maintained in cell culture. Proc Natl Acad Sci USA 88:7834-7838.

Benardo LS, Prince DA (1982) Cholinergic pharmacology of mammalian hippocampal pyramidal cells. Neuroscience 7:1703-1712.

Burnstock G (2004) Cotransmission. Curr Opin Pharmacol 4:47-52.

Caulfield MP, Birdsall NJ (1998) International Union of Pharmacology. XVII. Classification of muscarinic acetylcholine receptors. Pharmacol Rev 50:279-290.

Cole AE, Nicoll RA (1984) Characterization of a slow cholinergic postsynaptic potential recorded in vitro from rat hippocampal pyramidal cells. J Physiol (Lond) 352:173-188.

Coyle JT, Price DL, DeLong MA (1983) Alzheimer's disease: a disorder of cortical cholinergic innervation. Science 219:1184-1190.

Csaki A, Kocsis K, Halasz B, Kiss J (2000) Localization of glutamatergic/ aspartatergic neurons projecting to the hypothalamic paraventricular nucleus studied by retrograde transport of $\left[{ }^{3} \mathrm{H}\right] \mathrm{D}$-aspartate autoradiography. Neuroscience 101:637-655.

Csaki A, Kocsis K, Kiss J, Halasz B (2002) Localization of putative glutamatergic/aspartatergic neurons projecting to the supraoptic nucleus area of the rat hypothalamus. Eur J Neurosci 16:55-68.

Docherty M, Bradford HF, Wu J-Y (1987) Co-release of glutamate and aspartate from cholinergic and GABAergic synaptosomes. Nature 330:64-66.

Dudar JD, Szerb JC (1969) The effect of topically applied atropine on resting and evoked cortical acetylcholine release. J Physiol (Lond) 203:741-762.

Fremeau Jr RT, Troyer MD, Pahner I, Nygaard GO, Tran CH, Reimer RJ, Bellocchio EF, Fortin D, Storm-Mathisen J, Edwards RH (2001) The 
expression of vesicular glutamate transporters defines two classes of excitatory synapse. Neuron 31:247-260.

Furuta T, Koyano K, Tomioka R, Yanagawa Y, Kaneko TK (2004) GABAergic basal forebrain neurons that express receptor for neurokinin $\mathrm{B}$ and send axons to the cerebral cortex. J Comp Neurol 473:43-58.

Gahwiler BH, Brown DA (1985) Functional innervation of cultured hippocampal neurones by cholinergic afferents from co-cultured septal explants. Nature 313:577-579.

Gritti I, Mainville L, Jones BF (1993) Codistribution of GABA- with acetylcholine-synthesizing neurons in the basal forebrain of the rat. J Comp Neurol 329:438-457.

Gritti I, Mainville L, Mancia M, Jones BF (1997) GABAergic and other noncholinergic basal forebrain neurons, together with cholinergic neurons, project to the mesocortex and isocortex in the rat. J Comp Neurol 383:163-177.

Gritti I, Manns ID, Mainville L, Jones BF (2003) Parvalbumin, calbindin, or calretinin in cortically projecting and GABAergic, cholinergic, or glutamatergic basal forebrain neurons of the rat. J Comp Neurol 458:11-31.

Haas HL (1982) Cholinergic disinhibition in hippocampal slices of the rat. Brain Res 233:200-204.

Hajszan T, Alreja M, Leranth C (2004) Intrinsic vesicular glutamate transporter 2-immunoreactive input to septohippocampal parvalbumin-containing neurons: novel glutamatergic local circuit cells. Hippocampus 14:499-509.

Harkany T, Mulder J, Sasvari M, Abraham I, Konya C, Zarandi M, Penke B, Luiten PG, Nyakas C (1999) N-methyl-D-aspartate receptor antagonist MK-801 and radical scavengers protect cholinergic nucleus basalis neurons against beta-amyloid neurotoxicity. Neurobiol Dis 6:109-121.

Israel M, Lesbats B, Bruner J (1993) Glutamate and acetylcholine release from cholinergic nerve terminals, a calcium control of the specificity of the release mechanism. Neurochem Int 22:53-58.

Kiss J, Csaki A, Bokor H, Kocsis K, Kocsis B (2002) Possible glutamatergic/ aspartatergic projections to the supramammillary nucleus and their origins in the rat studied by selective $\left[{ }^{3} \mathrm{H}\right] \mathrm{D}$-aspartate labelling and immunocytochemistry. Neuroscience 111:671-691.

Landis SC (1976) Rat sympathetic neurons and cardiac myocytes developing in microcultures: correlation of the fine structure of endings with neurotransmitter function in single neurons. Proc Natl Acad Sci USA $73: 4220-4224$

Leranth C, Frotscher M (1989) Organization of the septal region in the rat brain: cholinergic-GABAergic interconnections and the termination of hippocampo-septal fibers. J Comp Neurol 289:304-314.

Li WC, Soffe SR, Roberts A (2004) Glutamate and acetylcholine corelease at developing synapses. Proc Natl Acad Sci USA 101:15488-15493.

Lin W, McKinney K, Liu L, Lakhlani S, Jennes L (2003) Distribution of vesicular glutamate transporter-2 messenger ribonucleic acid and protein in the septum-hypothalamus of the rat. Endocrinology 144:662-670.

Lucas-Meunier E, Fossier P, Baux G, Amar M (2003) Cholinergic modulation of the cortical neuronal network. Pflügers Arch 446:17-29.

Manns ID, Mainville L, Jones BF (2001) Evidence for glutamate, in addition to acetylcholine and GABA, neurotransmitter synthesis in basal forebrain neurons projecting to the entorhinal cortex. Neuroscience 107:249-263.

Manns ID, Alonso A, Jones BF (2003) Rhythmically discharging basal forebrain units comprise cholinergic, GABAergic, and putative glutamatergic cells. J Neurophysiol 89:1057-1066.

Mennerick SJ, Que J, Benz A, Zorumski CF (1995) Passive and synaptic properties of hippocampal neurons grown in microcultures and in mass cultures. J Neurophysiol 73:320-332.

Mentis GZ, Alvarez FJ, Bonnot A, Richards DS, Gonzales-Forero D, Zerda R, O’Donovan MJ (2005) Noncholinergic excitatory actions of motoneurons in the neonatal mammalian spinal cord. Proc Natl Acad Sci USA 102:7344-7349.

Mesulam MM, Mufson EJ, Wainer BH, Levey AI (1983) Central cholinergic pathways in the rat: an overview based on an alternative nomenclature (Ch1-Ch6). Neuroscience 10:1185-1201.

Mrzljak L, Pappy M, Leranth C, Goldman-Rakic PS (1995) Cholinergic synaptic circuitry in the macaque prefrontal cortex. J Comp Neurol 357:603-617.

Nishimura H, Restrepo CE, Rynge JY, Kiehn O (2005) Mammalian motor neurons corelease glutamate and acetylcholine at central synapses. Proc Natl Acad Sci USA 102:5245-5249.

Page KJ, Everitt BJ (1995) The distribution of neurons coexpressing immunoreactivity to BMPA-sensitive glutamate receptor subtypes (GluR1-4) and nerve growth factor receptor in the rat basal forebrain. Eur J Neurosci 7:1022-1033.

Perry EK, Tomlinson BE, Blessed G, Bergmann K, Gibsoa PH, Perry RH (1978) Correlation of cholinergic abnormalities with senile plaque and mental test scores in senile dementia. Br Med J 2:1457-1459.

Pfrieger FW, Gottmann K, Lux HD (1994) Kinetics of GABAB receptormediated inhibition of calcium currents and excitatory synaptic transmission in hippocampal neurons in vitro. Neuron 12:97-107.

Potter DD, Landis SC, Furshpan EJ (1980) Dual function during development of rat sympathetic neurones in culture. J Exp Biol 89:57-71.

Price JL, Stern R (1983) Individual cells in the nucleus basalis-diagonal band complex have restricted axonal projections to the cerebral cortex in the rat. Brain Res 269:352-356.

Rae J, Cooper K, Gates P, Watsky M (1991) Low access resistance perforated patch recordings using amphotericin B. J Neurosci Methods 37:15-26.

Segal MM (1991) Epileptiform activity in microcultures containing one excitatory hippocampal neuron. J Neurophysiol 65:761-770.

Sim JA, Allen TGJ (1998) Morphological and membrane properties of rat magnocellular basal forebrain neurons maintained in culture. J Neurophysiol 80:1653-1669.

Sim JA, Griffith WH (1996) Muscarinic inhibition of glutamatergic transmissions onto rat magnocellular basal forebrain neurons in a thin-slice preparation. Eur J Neurosci 8:880-891.

Sotty F, Danik M, Manseau F, Laplante F, Quirion R, Williams SM (2003) Distinct electrophysiological properties of glutamatergic, cholinergic and GABAergic rat septohippocampal neurons: novel implications for hippocampal rhythmicity. J Physiol (Lond) 551:927-943.

Umbriaco D, Watkins KC, Descarries L, Cozzari C, Hartman BK (1994) Ultrastructural and morphometric features of the acetylcholine innervation in adult rat parietal cortex: an electron microscopic study in serial sections. J Comp Neurol 348:351-373.

Waters DJ, Allen TGJ (1998) $\mathrm{Ca}^{2+}$-permeable non-NMDA glutamate receptors in rat magnocellular basal forebrain neurons. J Physiol (Lond) 508:453-469.

Wenk GL (1997) The nucleus basalis magnocellularis cholinergic system: one hundred years of progress. Neurobiol Learn Mem 67:85-95.

Whitehouse PJ, Price DL, Struble RG, Clark AW, Cotle JT, DeLong MR (1982) Alzheimers disease and senile dementia: loss of neurons in the basal forebrain. Science 215:1237-1239.

Yamada KA, Tang CM (1993) Benzothiadiazides inhibit rapid glutamate receptor desensitization and enhance glutamatergic synaptic currents. J Neurosci 13:3904-3915.

Zaborszky L, Carlsen J, Brashear HR, Heimer L (1986) Cholinergic and GABAergic afferents to the olfactory bulb in the rat with special emphasis on the projection neurons in the nucleus of the horizontal limb of the diagonal band. J Comp Neurol 243:488-509.

Zaborszky L, Pang K, Somogyi J, Nadazdy Z, Kallo I (1999) The basal forebrain corticopetal system revisited. Ann NY Acad Sci 877:339-367.

Zhou J, Shapiro MS, Hille B (1997) Speed of $\mathrm{Ca}^{2+}$ channel modulation by neurotransmitters in rat sympathetic neurons. J Neurophysiol 77:20402048. 